\title{
VEGF Inhibitors Do Not Increase D-dimer Levels in Colorectal Cancer Patients Without Venous Thromboembolism: A Retrospective Non-inferiority Analysis
}

\author{
HIROKAZU TOSHIMA, TOSHIKAZU IKUSUE, ATSUSHI HISAMATSU, \\ KOUJI KOBAYASHI, HIROO ISHIDA and KEN SHIMADA \\ Medical Oncology, Showa University Koto Toyosu Hospital, Tokyo, Japan
}

\begin{abstract}
Background/Aim: If VEGF inhibitors contribute to an increase in D-dimer levels, they may adversely affect the diagnosis of venous thromboembolism (VTE). Consequently, this retrospective study examined the effects of VEGF inhibitors on D-dimer levels in colorectal cancer patients. Patients and Methods: A total of 104 colorectal cancer patients who received chemotherapy, were included in this study. To perform D-dimer analysis, patients were divided into two analysis targets: patients with VTE and without VTE. Statistical analysis included a natural logarithmic transformation of D-dimer data. Results: In the $D$-dimer analysis of non-VTE patients, the natural logarithm $D$-dimer mean difference was -0.186, with a $95 \%$ CI of -0.525 to 0.154. The upper limit of the 95\%CI (0.154) did not exceed the non-inferiority margin ( $\triangle$ ) of 0.199, and therefore met the non-inferiority criteria. Conclusion: VEGF inhibitors don't contribute to increased D-dimer levels in colorectal cancer patients without VTE.
\end{abstract}

Vascular endothelial growth factor (VEGF) inhibitors, introduced by Folkman et al., are antiangiogenic therapybased drugs (1) that inhibit tumor growth, invasion, and metastasis by inhibiting tumor angiogenesis. Approved in 2004 by the U.S. Food and Drug Administration (FDA), bevacizumab was the first VEGF inhibitor with indications for various cancers, including colorectal cancer. In Japan,

This article is freely accessible online.

Correspondence to: Hirokazu Toshima, MD, Ph.D., Medical Oncology, Showa University Koto Toyosu Hospital, 5-1-38 Toyosu, Koto-ku, Tokyo 135-8577, Japan. Tel: +81 362046000, Fax: +81 362046396,e-mail: showa_northern@yahoo.co.jp

Key Words: Vascular endothelial growth factor inhibitor, chemotherapy, Pan-Asian adapted ESMO consensus guidelines, deep vein thrombosis, pulmonary embolism. ramucirumab and aflibercept have also been approved as VEGF inhibitors for colorectal cancer treatment. VEGF inhibitors play an important role in colorectal cancer chemotherapy, and the Pan-Asian Adapted European Society for Medical Oncology (ESMO) Consensus Guidelines also recommends the use of bevacizumab combination therapies in many patients (2).

Although VEGF inhibitors have been widely used in various cancers, consequent adverse events such as venous thromboembolism (VTE) have been reported. In a multinational phase-III clinical trial (NO16966) in which bevacizumab was approved for colorectal cancer treatment, VTE (CTCAE ver3.0 all grade) incidence was $12.4 \%(3,4)$. Similarly, adverse events have also been reported in ramucirumab- and aflibercept-treated patients; hence, in our routine medical care, these drugs are used with caution.

The high negative predictive value of D-dimer in VTE diagnosis is widely known; thus, it is very useful in diagnosis by exclusion (5). In addition, D-dimer is reported as a useful VTE predictive marker even in malignant tumor patients (6). On the other hand, its positive predictive value is low because various factors such as surgery, infection, disseminated intravascular coagulation (DIC), liver cirrhosis, and malignant tumors increase D-dimer levels. In other words, while patients with negative D-dimer test results are very unlikely to develop VTE, those with positive D-dimer test results do not always develop VTE.

As described above, VEGF inhibitors have been known to increase the risk of VTE. However, if they contribute to an increase in D-dimer levels, which are useful in VTE prediction, they may further reduce the positive predictive value. Consequently, this retrospective study examined the effects of VEGF inhibitors on D-dimer levels in colorectal cancer patients.

\section{Patients and Methods}

A total of 104 colorectal cancer patients who received adjuvant chemotherapy after surgery and systemic chemotherapy for 
unresectable or recurrent metastasis between March 2014 and May 2018 at the Department of Medical Oncology (Showa University Koto Toyosu Hospital), were included in this study. Approval was given by the institutional review board of the Showa University Koto Toyosu Hospital (approval date: October 2018), and the study was conducted in accordance with the Helsinki Declaration guidelines. This retrospective study was conducted using our clinical database, all patient data were protected and kept confidential, and during data acquisition, personal information that could be used to identify patients was eliminated. Through the hospitals' homepage, patients were informed of the purpose of the study, with the option to optout; hence, additional patient consent was not required.

Study background. Once a month during chemotherapy, D-dimer levels were routinely measured to detect VTE in the early stages. An automated coagulation analyzer (Coapresta 2000; Sekisui Medical Co., Ltd., Tokyo, Japan) was used to analyze all specimens. Nanopia D-dimer (Sekisui Medical Co., Ltd, Tokyo, Japan) was used as a reagent and the reference range of D-dimer levels in the measurement method was $1.0 \mu \mathrm{g} / \mathrm{ml}$ or less. When D-dimer levels exceeded this reference range, a contrast-enhanced Computed Tomography (CT) had been performed to exclude pulmonary embolism (PE) and deep vein thrombosis (DVT), following a VTE protocol (pulmonary arterial and lower extremity venous phase). To perform D-dimer analysis in our routine medical care, patients were divided into two analysis targets: patients with VTE (D-dimer analysis of VTE patients) and without VTE (D-dimer analysis of non-VTE patients) (Figure 1).

$D$-dimer analysis of VTE patients: Evaluation of D-dimer levels in VTE patients at diagnosis. D-dimer levels at the time of VTE diagnosis were extracted retrospectively. Analysis targets were divided into the VEGF inhibitor group (i.e., VEGF inhibitor-treated group at the time of VTE diagnosis) and the non-VEGF inhibitor group (i.e., non-VEGF inhibitor-treated group at the time of VTE diagnosis), to compare D-dimer levels.

$D$-dimer analysis of non-VTE patients: Evaluation of the highest Ddimer level in non-VTE patients. The highest D-dimer levels in the clinical course during chemotherapy were extracted retrospectively. Analysis targets were divided into the VEGF inhibitor group (i.e., VEGF inhibitor-treated group at the highest D-dimer level) and the non-VEGF inhibitor group (i.e., non-VEGF inhibitor-treated group at the highest D-dimer level), to compare D-dimer levels.

Statistical analyses. D-dimer data from the different groups were not normally distributed; hence, they were presented as medians (interquartile range), and box-and-whisker plots were used for visual evaluation. Statistical analysis inlcuded a natural logarithmic transformation of D-dimer data to approximate normal distribution. After testing variance homogeneity, the Student's $t$-test and one-way analysis of variance (ANOVA) were used to compare the means of the two groups. A $p$-value less than 0.05 (two-tailed) was considered statistically significant.

Regarding non-inferiority clinical trials, U.S. FDA guidelines recommend setting two margins: M1 and M2 (7). The non-inferiority margin $(\Delta)$ is an acceptable range of ratios or differences between the two groups compared. As D-dimer cut-off value (differential values) for VTE onset, one study used $1.44 \mu \mathrm{g} / \mathrm{ml}$ (8), which was also used in "the Vienna prediction model" to distinguish risk of

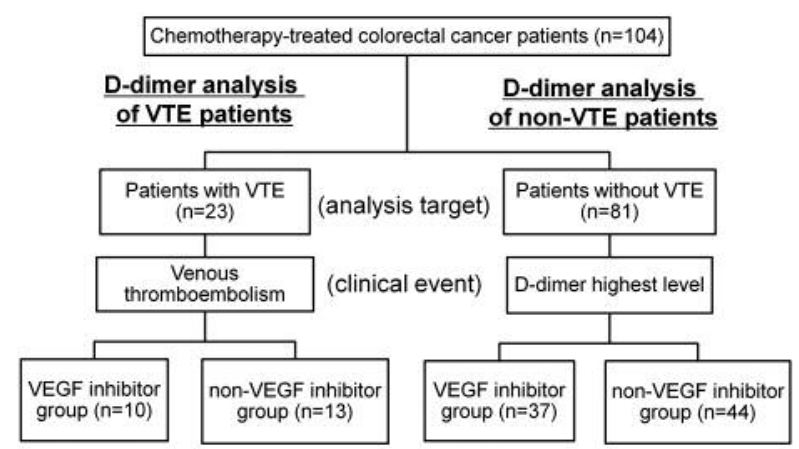

Figure 1. Patient disposition.

VTE recurrence (9). It should had been noted that the comparison of D-dimer levels due to different reagents, but this value was $44 \%$ higher than the upper limit of our D-dimer reference range and could be used as M1. In addition, a previous prospective non-inferiority trial used $30 \%$ as the D-dimer non-inferiority margin (10). Therefore, we set $50 \%$ of this $\mathrm{M} 1$ as M2, and decided the non-inferiority margin $(\Delta)$ of this study to be $22 \%$. This non-inferiority margin $(\Delta)$ of Ddimer levels was also appropriate from a clinical point of view.

The arithmetic mean difference in natural logarithm D-dimer (ln $\mathrm{D}$-dimer) corresponds to the geometric mean ratio in D-dimer. When the upper limit of the geometric mean ratio in D-dimer was 1.22 (non-inferiority margin of $22 \%$ ), the upper limit of the arithmetic mean difference after natural logarithm transformation was 0.199. This statistical approach is also used in the bioequivalence studies (11). Non-inferiority, which means that VEGF inhibitors did not contribute to an increase in D-dimer levels, was defined as $95 \%$ confidence interval (CI) of the arithmetic mean difference in $\ln$ D-dimer less than 0.199 from the above. All statistical analyses were performed using SPSS Statistics version 19.0 (IBM Corp., Armonk, NY, USA).

\section{Results}

The 104 colorectal cancer patients consisted of 23 patients with VTE $(22.1 \%)$ and 81 without VTE (77.9\%). There were 67 patients $(64.4 \%)$ who had been treated with bevacizumab, $3(2.9 \%)$ with ramucirumab, and $3(2.9 \%)$ with aflibercept (other baseline characteristics are shown in Table I). Statistically significant differences in some characteristics such as VEGF inhibitor history, chemotherapy target, and the onset of clinical events were observed. There were no statistically significant differences in patients who had previously received antithrombotic therapy to affect D-dimer levels.

D-dimer analysis of VTE patients. The median D-dimer levels were $5.2 \mu \mathrm{g} / \mathrm{ml}$ (interquartile range=3.6-7.8 $\mu \mathrm{g} / \mathrm{ml}$ ) and $4.7 \mu \mathrm{g} / \mathrm{ml}$ (interquartile range $=2.3-11.5 \mu \mathrm{g} / \mathrm{ml}$ ) in the VEGF and non-VEGF inhibitor groups, respectively. The box-and-whisker plots of D-dimer levels of both groups are shown in Figure 2A. There was no significant difference 
Table I. Demographic and baseline characteristics of patients $(n=104)$.

\begin{tabular}{|c|c|c|c|c|c|c|}
\hline \multirow{2}{*}{$\begin{array}{l}\text { Analysis target } \\
\text { Clinical event } \\
\text { VEGF inhibitor-treated } \\
\text { at the event appearance }\end{array}$} & \multicolumn{3}{|c|}{$\begin{array}{l}\text { D-dimer analysis of VTE patients } \\
\text { Patients with VTE }(\mathrm{n}=23) \\
\text { Venous thromboembolism }\end{array}$} & \multicolumn{3}{|c|}{$\begin{array}{c}\text { D-dimer analysis of non-VTE patients } \\
\text { Patients without VTE }(\mathrm{n}=81) \\
\text { D-dimer highest level }\end{array}$} \\
\hline & $\begin{array}{l}\text { VEGF inhibitor } \\
\text { group }(n=10)\end{array}$ & $\begin{array}{c}\text { Non-VEGF } \\
\text { inhibitor group }(n=13)\end{array}$ & $p$-Value & $\begin{array}{l}\text { VEGF inhibitor } \\
\text { group }(n=37)\end{array}$ & $\begin{array}{l}\text { Non-VEGF inhibitor } \\
\text { group }(n=44)\end{array}$ & $p$-Value \\
\hline Age-year & $72.5(62-75)$ & $71(66-75)$ & 0.95 & $66(60-73)$ & $67(59-71)$ & 0.59 \\
\hline \multicolumn{7}{|l|}{ Gender-no. [\%] } \\
\hline Male & $6[60.0]$ & $6[46.2]$ & & $28[75.7]$ & $34[77.3]$ & \\
\hline Female & $4[40.0]$ & $7[53.8]$ & 0.41 & $9[24.3]$ & $10[22.7]$ & 0.87 \\
\hline \multicolumn{7}{|c|}{ Chemotherapy target-no. [\%] } \\
\hline Primary advanced & $8[80.0]$ & $9[69.2]$ & & $15[40.5]$ & $32[72.7]$ & \\
\hline Recurrence & $2[20.0]$ & $3[23.1]$ & & $22[59.5]$ & $10[22.7]$ & \\
\hline Adjuvant & $0[0]$ & $1[7.7]$ & 0.64 & $0[0]$ & $2[4.5]$ & 0.002 \\
\hline \multicolumn{7}{|l|}{ Administration history of } \\
\hline Prior antithrombotic & & & & & & \\
\hline therapy-no. [\%] & $0[0]$ & $1[7.7]$ & 0.57 & $1[2.7]$ & $1[2.3]$ & 0.71 \\
\hline Reference period-day & $575(403-975)$ & $510(338-724)$ & 0.54 & $679(395-1071)$ & $596(388-949)$ & 0.23 \\
\hline \multicolumn{7}{|l|}{ At the event appearance } \\
\hline \multicolumn{7}{|c|}{ VEGF inhibitor drug-no. [\%] } \\
\hline Bevacizumab & $10[100]$ & - & & $36[97.3]$ & - & \\
\hline Ramucirumab & $0[0]$ & - & & $0[0]$ & - & \\
\hline Aflibercept & $0[0]$ & - & & $1[2.7]$ & - & \\
\hline \multicolumn{7}{|l|}{ Number of chemotherapy } \\
\hline \multicolumn{7}{|l|}{ lines-no. [\%] } \\
\hline 0 & $0[0]$ & $2[15.4]$ & & $0[0]$ & $9[20.5]$ & \\
\hline 1 & $6[60.0]$ & $5[38.5]$ & & $27[73.0]$ & $19[43.2]$ & \\
\hline 2 & $2[20.0]$ & $4[30.8]$ & & $8[21.6]$ & $5[11.4]$ & \\
\hline 3 & $1[10.0]$ & $0[0]$ & & $1[2.7]$ & $2[4.5]$ & \\
\hline 4 or more & $1[10.0]$ & $2[15.4]$ & 0.44 & $1[2.7]$ & $9[20.5]$ & 0.002 \\
\hline \multicolumn{7}{|l|}{$\begin{array}{l}\text { ECOG performance } \\
\text { status-no. [\%] }\end{array}$} \\
\hline 0 & $4[40.0]$ & $5[38.5]$ & & $27[73.0]$ & $28[63.6]$ & \\
\hline 1 & $6[60.0]$ & $4[30.8]$ & & $8[21.6]$ & $10[22.7]$ & \\
\hline 2 & $0[0]$ & $3[23.1]$ & & $2[5.4]$ & $4[9.1]$ & \\
\hline 3 & $0[0]$ & $1[7.7]$ & & $0[0]$ & $2[4.5]$ & \\
\hline 4 & $0[0]$ & $0[0]$ & 0.24 & $0[0]$ & $0[0]$ & 0.51 \\
\hline Body surface area $-\mathrm{m}^{2}$ & $1.51(1.45-1.64)$ & $1.53(1.38-1.71)$ & 0.95 & $1.66(1.50-1.78)$ & $1.60(1.50-1.71)$ & 0.21 \\
\hline
\end{tabular}

Notes: $p$-Values indicate differences between groups by Mann-Whitney $U$-test, Chi-squared test or Fisher's exact test.

between the ln D-dimer means of the 2 groups $(p=0.88)$. The ln D-dimer mean difference was 0.064 , with a $95 \% \mathrm{CI}$ of -0.811 to 0.941 . The upper limit of the $95 \% \mathrm{CI}(0.941)$ exceeded the non-inferiority margin $(\Delta)$ of 0.199 , and therefore did not meet the non-inferiority criteria (Figure 3 ). The test results are shown in Table II.

D-dimer analysis of non-VTE patients. The median D-dimer levels were $2.5 \mu \mathrm{g} / \mathrm{ml}$ (interquartile range $=1.3-3.3 \mu \mathrm{g} / \mathrm{ml}$ ) and $2.3 \mu \mathrm{g} / \mathrm{ml}$ (interquartile range $=1.4-4.1 \mu \mathrm{g} / \mathrm{ml}$ ) in the VEGF and non-VEGF inhibitor groups, respectively. The box-and-whisker plots of D-dimer levels of both groups are shown in Figure 2B. There was no significant difference between the $\ln \mathrm{D}$-dimer means of the 2 groups $(p=0.28)$. The ln D-dimer mean difference was -0.186 , with a $95 \% \mathrm{CI}$ of -0.525 to 0.154 . The upper limit of the $95 \%$ CI (0.154) did not exceed the non-inferiority margin $(\Delta)$ of 0.199 , and therefore met the non-inferiority criteria (Figure 3 ). The test results are shown in Table II.

\section{Discussion}

The incidence of VTE in cancer patients is increasing annually (12), and is reportedly 4-8 times higher than in non- 

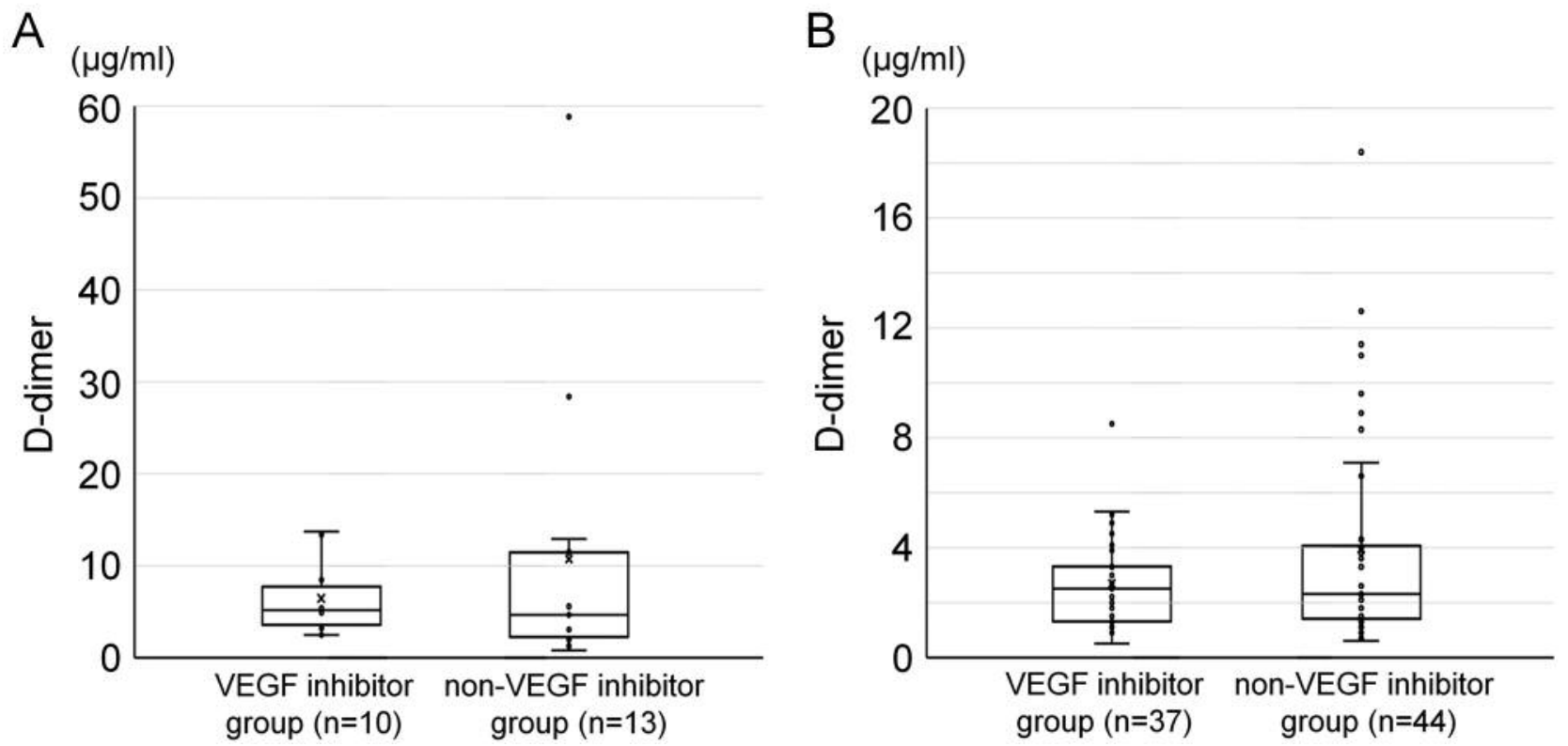

Figure 2. Box-and-whisker Plot of D-dimer analysis of VTE patients (A) and D-dimer analysis of non-VTE patients (B).

cancer patients (13-15). The most common cause of death in cancer patients is reportedly the primary disease, followed by VTE (16). Therefore, early detection and treatment of VTE are crucial.

As described above, D-dimer levels were routinely measured to detect VTE in the early stages. In this study, there was no significant difference between the D-dimer levels of the VEGF and non-VEGF inhibitor groups. The non-inferiority criteria were met in the D-dimer analysis of non-VTE patients, but not in that of VTE patients. Additionally, the accumulation of D-dimer in both groups was visually evaluated using box-and-whisker plots. In Figure $2 \mathrm{~A}$ and $\mathrm{B}$, the boxes overlap including both medians, not showing that there was difference in the D-dimer levels between the two groups.

The D-dimer analysis of non-VTE patients demonstrated the non-inferiority, suggesting that without VTE, VEGF inhibitors did not contribute to an increase in D-dimer levels in colorectal cancer patients.

To consider the factors that did not meet the noninferiority criteria in the D-dimer analysis of VTE patients despite not showing statistical significance, we focus on the between-group and within-group variation. D-dimer analysis of VTE patients showed that within-group and betweengroup variation accounted for $99.91 \%$ and $0.09 \%$ of the total variation, respectively (Table II). The large within-group variation indicates the variability of $\mathrm{D}$-dimer levels within each group, and the larger the variability, the larger the CI range. Since D-dimer is a degradation product of a cross- linked fibrin, it has various structures and molecular weights, with high individual differences $(17,18)$. The low specificity and low positive predictive value of D-dimer in VTE diagnosis also contributes to an increase in variability (19). Variability due to these factors may have contributed to not meeting, statistically, the non-inferiority criteria in this study.

As a degradation product of a cross-linked fibrin, D-dimer is indicative of the presence of secondary fibrinolysis. In other words, an increase in D-dimer levels suggests preceding thrombus formation. VTE is caused by coagulation and fibrinolysis imbalance. Although cancer and VEGF inhibitors are risk factors for thrombus formation, not all cancer patients or those treated with VEGF inhibitors develop VTE. Virchow's triad (venous stasis, vessel wall injury, and hypercoagulability), which was introduced by Virchow et al. in 1856, is supported to date (20). In VEGF inhibitor-induced thrombus formation, the inhibitors reduce vascular endothelial cell repair ability via vascular endothelial growth factor receptor 2 (VEGFR-2), and platelet aggregation inhibition via nitric oxide (NO) and prostacyclin (PGI2) $(21,22)$. Although these mechanisms are consistent with Virchow's triad, if coagulation and fibrinolysis balance is maintained, patients may not develop VTE, even in hypercoagulability conditions. In this equilibrium state, Ddimer levels are also difficult to increase due to low levels of cross-linked fibrin. The specificity of the D-dimer in secondary fibrinolytic systems could be one of the reasons why VEGF inhibitors do not contribute to increased D-dimer levels in colorectal cancer patients without VTE. 


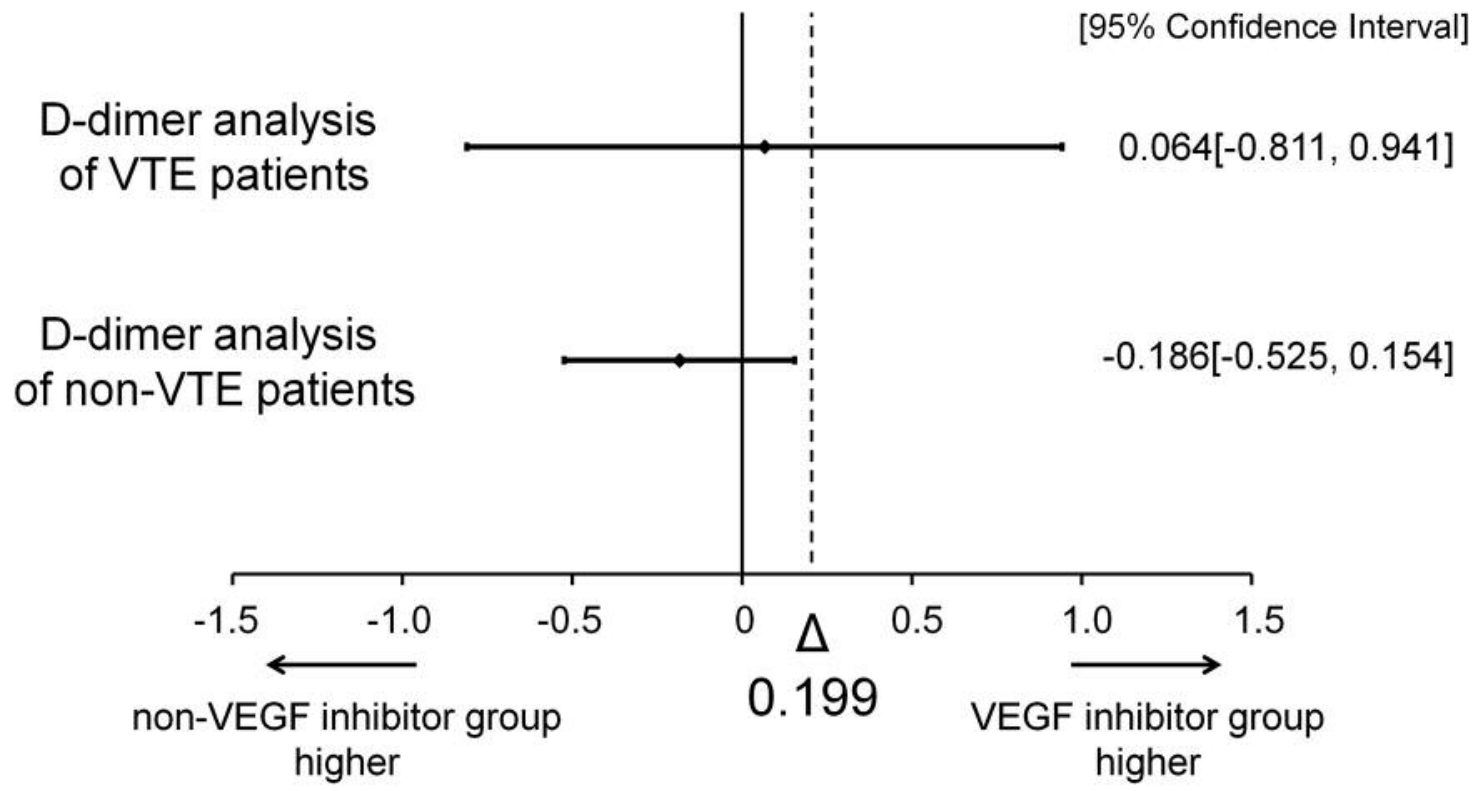

Figure 3. Difference in the average values of natural logarithmic D-dimer.

Table II. Statistical analysis results.

\begin{tabular}{|c|c|c|c|c|c|c|c|c|}
\hline & \multirow{2}{*}{$\begin{array}{c}\text { Difference } \\
\text { in the average } \\
\text { values of } \\
\text { ln D-dimer }\end{array}$} & \multicolumn{2}{|c|}{$95 \%$ Confidence interval } & \multicolumn{3}{|c|}{ Source of variation } & \multirow{2}{*}{$\begin{array}{c}\text { Coefficient of } \\
\text { variation }\end{array}$} & \multirow[t]{2}{*}{$p$-Value } \\
\hline & & Lower limit & Upper limit & Total & $\begin{array}{c}\text { Between group } \\
{[\%]}\end{array}$ & $\begin{array}{c}\text { Within group } \\
{[\%]}\end{array}$ & & \\
\hline $\begin{array}{l}\text { D-dimer analysis } \\
\text { of VTE patients }\end{array}$ & 0.064 & -0.811 & 0.941 & 21.08 & $0.02[0.09 \%]$ & $21.06[99.91 \%]$ & 0.59 & 0.88 \\
\hline $\begin{array}{l}\text { D-dimer analysis } \\
\text { of non-VTE patients }\end{array}$ & -0.186 & -0.525 & 0.154 & 46.87 & $0.69[1.47 \%]$ & $46.18[98.53 \%]$ & 0.85 & 0.28 \\
\hline
\end{tabular}

The incidence of VTE in colorectal cancer patients included in this study was $22.1 \%$, which was higher than that observed in the NO16966 trial. However, these patients included those with asymptomatic VTE and peripheral DVT. Using D-dimer levels as a predictor, we work actively on VTE detection and the VTE "detection rate" reflects the effort made. While there are various theories on therapeutic intervention in patients with asymptomatic VTE and peripheral DVT, our department is actively working on it. Peripheral DVT patients with cancer have also been shown to have a much poorer prognosis than peripheral DVT patients without cancer $(23,24)$. The revised guidelines of the American College of Chest Physicians (ACCP; 2016) also recommends therapeutic intervention in patients with active cancer and peripheral DVT (25). Active detection and treatment of VTE has led to symptomatic or severe VTE prevention.
This study of retrospectively collected data with nonrandomized treatment assignment has several limitations such as intergroup differences in baseline characteristics. Also, the biases of the attending physicians might have affected the choice and use of VEGF inhibitors. However, based on existing literature, this study is the first to examine the relationship between VEGF inhibitors and D-dimer levels; hence, future studies can use these results to obtain evidence without bias.

\section{Conclusion}

VTE is a dangerous condition that can lead to death. This study demonstrated that VEGF inhibitors do not contribute to increased D-dimer levels in colorectal cancer patients without VTE. Therefore, increased D-dimer levels in VEGF inhibitor- 
treated patients suggest a complication of VTE, instead of false positive side effects. In other words, it is dangerous to deny the possibility of VTE just based on cancer/medication status of patients with positive D-dimer results. Thus, it is crucial to perform medical imaging tests to reject the possibility of VTE.

\section{Conflicts of Interest}

The Authors have no conflicts of interest in regard to this study.

\section{Authors' Contributions}

HT designed this study. HT, TI, AH and KK performed data collection. HT drafted and revised the manuscript. MI and SK supervised this study and revised the manuscript. All Authors of this paper have read and approved the final version submitted.

\section{Acknowledgements}

The Authors would like to thank Editage (www.editage.jp) for English language editing.

\section{References}

1 Folkman J: Tumor angiogenesis: Therapeutic implications. N Engl J Med 285: 1182-1186,1971. PMID: 4938153. DOI: 10.1056/NEJM197111182852108

2 Yoshino T, Arnold D, Taniguchi H, Pentheroudakis G, Yamazaki K, Xu RH, Kim TW, Ismail F, Tan IB, Yeh KH, Grothey A, Zhang S, Ahn JB, Mastura MY, Chong D, Chen LT, Kopetz S, EguchiNakajima T, Ebi H, Ohtsu A, Cervantes A, Muro K, Tabernero J, Minami H, Ciardiello F and Douillard JY: Pan-Asian adapted ESMO consensus guidelines for the management of patients with metastatic colorectal cancer: a JSMO-ESMO initiative endorsed by CSCO, KACO, MOS, SSO and TOS. Ann Oncol 29: 4470,2018. PMID: 29155929. DOI: 10.1093/annonc/mdx738

3 Saltz LB, Clarke S, Diaz-Rubio E, Scheithauer W, Figer A, Wong R, Koski S, Lichinitser M, Yang TS, Rivera F, Couture F, Sirzen $\mathrm{F}$ and Cassidy J: Bevacizumab in combination with oxaliplatinbased chemotherapy as first-line therapy in metastatic colorectal cancer: a randomized phase III study. J Clin Oncol 26: 20132019, 2008. PMID: 18421054. DOI: 10.1200/JCO.2007.14.9930

4 Hurwitz HI, Saltz LB, Van Cutsem E, Cassidy J, Wiedemann J, Sirzen F, Lyman GH and Rohr UP: Venous thromboembolic events with chemotherapy plus bevacizumab: a pooled analysis of patients in randomized phase II nd III studies. J Clin Oncol 29: 1757-1764, 2011. PMID: 21422411. DOI: 10.1200/JCO.2010.32.3220

5 Wells PS, Owen C, Doucette S, Fergusson D and Tran H: Does this patient have deep vein thrombosis? JAMA 295: 199-207, 2006. PMID: 16403932. DOI: 10.1001/jama.295.2.199

6 Ferroni P, Martini F, Portarena I, Massimiani G, Riondino S, La Farina F, Mariotti S, Guadagni F and Roselli M: Novel highsensitive D-dimer determination predicts chemotherapyassociated venous thromboembolism in intermediate risk lung cancer patients. Clin Lung Cancer 13: 482-487, 2012. PMID: 22591606. DOI: 10.1016/j.cllc.2012.03.005

7 U.S. Food and Drug Administration: Non-Inferiority Clinical Trials to Establish Effectiveness Guidance for Industry, 2016. Available at
https://www.fda.gov/downloads/Drugs/GuidanceComplianceRegula toryInformation/Guidances/UCM202140.pdf Last accessed on 21th July 2019.

8 Ay C, Vormittag R, Dunkler D, Simanek R, Chiriac AL, Drach J, Quehenberger P, Wagner O, Zielinski C and Pabinger I: D-dimer and prothrombin fragment $1+2$ predict venous thromboembolism in patients with cancer: results from the Vienna Cancer and Thrombosis Study. J Clin Oncol 27: 4124-4129, 2009. PMID: 19636003. DOI: $10.1200 / J C O .2008 .21 .7752$

9 Thaler J, Ay C and Pabinger I: Venous thromboembolism in cancer patients - risk scores and recent randomised controlled trials. Thromb Haemost 108: 1042-1048, 2012. PMID: 22836491. DOI: 10.1160/TH12-04-0241

10 Greilich PE, Jessen ME, Satyanarayana N, Whitten CW, Nuttall GA, Beckham JM, Wall MH and Butterworth JF: The effect of epsilon-aminocaproic acid and aprotinin on fibrinolysis and blood loss in patients undergoing primary, isolated coronary artery bypass surgery: a randomized, double-blind, placebocontrolled, noninferiority trial. Anesth Analg 109: 15-24, 2009. PMID: 19535691. DOI: 10.1213/ane.0b013e3181a40b5d

11 U.S. Food and Drug Administration: Guidance for industry: Statistical approaches to establishing bioequivalence, 2001. Available at https://www.fda.gov/downloads/drugs/guidances/ucm070244.pdf Last accessed on 15th August 2019.

12 Walker AJ, Card TR, West J, Crooks C and Grainge MJ: Incidence of venous thromboembolism in patients with cancer - a cohort study using linked United Kingdom databases. Eur J Cancer 49: 14041413, 2013. PMID: 23146958. DOI: 10.1016/j.ejca.2012.10.021

13 Heit JA, Silverstein MD, Mohr DN, Petterson TM, O'Fallon WM and Melton LJ 3rd: Risk factors for deep vein thrombosis and pulmonary embolism: a population-based case-control study. Arch Intern Med 160: 809-815, 2000. PMID: 21475600. DOI: $10.1159 / 000324584$

14 Blom JW, Doggen CJ, Osanto $\mathrm{S}$ and Rosendaal FR: Malignancies, prothrombotic mutations, and the risk of venous thrombosis. JAMA 293: 715-722, 2005. PMID: 15701913. DOI: 10.1001/jama.293.6.715

15 Cronin-Fenton DP, Sondergaard F, Pedersen LA, Fryzek JP, Cetin K, Acquavella J, Baron JA and Sorensen HT: Hospitalisation for venous thromboembolism in cancer patients and the general population: a population-based cohort study in Denmark, 1997-2006. Br J Cancer 103: 947-953, 2010. PMID: 20842120. DOI: $10.1038 /$ sj.bjc.6605883

16 Khorana AA: Venous thromboembolism and prognosis in cancer. Thromb Res 125: 490-493, 2010. PMID: 20097409. DOI: 10.1016/j.thromres.2009.12.023

17 Reber G and de Moerloose P: D-dimer assays for the exclusion of venous thromboembolism. Semin Thromb Hemost 26: 619624, 2000. PMID: 11140798. DOI: 10.1055/s-2000-13217

18 Meijer P, Haverkate F, Kluft C, de Moerloose P, Verbruggen B and Spannagl M: A model for the harmonisation of test results of different quantitative D-dimer methods. Thromb Haemost 95: 567-572, 2006. PMID: 16525589. DOI: 10.1160/TH05-01-0042

19 Goodacre S, Sampson FC, Sutton AJ, Mason S and Morris F: Variation in the diagnostic performance of D-dimer for suspected deep vein thrombosis. QJM 98: 513-527, 2005. PMID: 15955795. DOI: 10.1093/qjmed/hci085

20 Virchow R: Ein Vortrag uber die Thrombose vom Jahre 1845. Gesammelte Abhandlungen zur wissenschaften Medizin, 478486,1856 . 
21 Kamba T and McDonald DM: Mechanisms of adverse effects of anti-VEGF therapy for cancer. Br J Cancer 96: 1788-1795, 2007. PMID: 17519900. DOI: 10.1038/sj.bjc.6603813

22 Verheul HM and Pinedo HM: Possible molecular mechanisms involved in the toxicity of angiogenesis inhibition. Nat Rev Cancer 7: 475-485, 2007. PMID: 17522716. DOI: $10.1038 /$ nrc2152

23 Dentali F, Pegoraro S, Barco S, di Minno MND, Mastroiacovo D, Pomero F, Lodigiani C, Bagna F, Sartori M, Barillari G, Mumoli N, Napolitano M, Passamonti SM, Benedetti R, Ageno W and Di Nisio M: Clinical course of isolated distal deep vein thrombosis in patients with active cancer: a multicenter cohort study. J Thromb Haemost 15: 1757-1763, 2017. PMID: 28639418. DOI: $10.1111 /$ jth.13761

24 Galanaud JP, Sevestre MA, Pernod G, Genty C, Richelet S, Kahn SR, Boulon C, Terrisse H, Quere I and Bosson JL: Longterm outcomes of cancer-related isolated distal deep vein thrombosis: the OPTIMEV study. J Thromb Haemost 15: 907916, 2017. PMID: 28266773. DOI: 10.1111/jth.13664
25 Kearon C, Akl EA, Ornelas J, Blaivas A, Jimenez D, Bounameaux H, Huisman M, King CS, Morris TA, Sood N, Stevens SM, Vintch JRE, Wells P, Woller SC and Moores L: Antithrombotic therapy for VTE disease: CHEST Guideline and Expert Panel Report. Chest 149: 315-352, 2016. PMID: 26867832. DOI: 10.1016/j.chest.2015.11.026
Received July 26, 2019

Revised August 15, 2019 Accepted August 21, 2019 